\title{
Sleep quality and communication aspects in children
}

\author{
Camila de Castro Corrêa ${ }^{a,}{ }^{*}$, Maria Renata José ${ }^{b}$, Eduardo Carvalho Andrade ${ }^{b}$, \\ Mariza Ribeiro Feniman ${ }^{\text {b }}$, Ana Paula Fukushiro ${ }^{\text {b }}$, Giédre Berretin-Felix ${ }^{\text {b }}$, \\ Luciana Paula Maximino ${ }^{\text {b }}$ \\ a Department of Ophthalmology, Otolaryngology and Head and Neck Surgery, Botucatu Medical School, State University São Paulo, UNESP, Botucatu, SP, \\ Brazil \\ ${ }^{\mathrm{b}}$ Department of Speech Therapy and Audiology, Bauru Dentistry School, University of São Paulo, USP, Bauru, SP, Brazil
}

\section{A R T I C L E I N F O}

\section{Article history:}

Received 3 April 2017

Received in revised form

21 June 2017

Accepted 24 June 2017

Available online 27 June 2017

\section{Keywords:}

Speech-language pathology

Stomatognathic system

Hearing

Language development disorders

Sleep

\begin{abstract}
A B S T R A C T
Objectives: To correlate quality of life of children in terms of sleep, with their oral language skills, auditory processing and orofacial myofunctional aspects.

Methods: Nineteen children (12 males and seven females, in the mean age 9.26) undergoing otorhinolaryngological and speech evaluations participated in this study. The OSA-18 questionnaire was applied, followed by verbal and nonverbal sequential memory tests, dichotic digit test, nonverbal dichotic test and Sustained Auditory Attention Ability Test, related to auditory processing. The Phonological Awareness Profile test, Rapid Automatized Naming and Phonological Working Memory were used for assessment of the phonological processing. Language was assessed by the ABFW Child Language Test, analyzing the phonological and lexical levels. Orofacial myofunctional aspects were evaluated through the MBGR Protocol. Statistical tests used: the Mann-Whitney Test, Fisher's exact test and Spearman Correlation.

Results: Relating the performance of children in all evaluations to the results obtained in the OSA-18, there was a statistically significant correlation in the phonological working memory for backward digits $(p=0.04)$; as well as in the breathing item $(p=0.03)$, posture of the mandible $(p=0.03)$ and mobility of lips ( $\mathrm{p}=0.04)$.

Conclusion: A correlation was seen between the sleep quality of life and the skills related to the phonological processing, specifically in the phonological working memory in backward digits, and related to orofacial myofunctional aspects.
\end{abstract}

(C) 2017 Elsevier B.V. All rights reserved.

\section{Introduction}

The nasal respiratory mode contributes to the adequate craniofacial and global development of the child, in the stomatognathic functions and the body posture [1], and has a suggestive relationship with a quality of sleep, since children who present oronasal or oral breathing may be more susceptible to snoring and/ or Obstructive Sleep Apnea [2], altered school achievement, bruxism, enuresis and nocturnal agitation [3].

\footnotetext{
* Corresponding author. Department of Ophtalmology, Otolaryngology and Head and Neck Surgery, Botucatu Medical School, State University São Paulo, UNESP, Distrito de Rubião Júnior, S/N, 18618-970 Botucatu, SP, Brazil.

E-mail addresses: camila.ccorrea@hotmail.com (C. de Castro Corrêa), mrenata. fono@yahoo.com.br (M.R. José), eduardocandrade@terra.com.br (E.C. Andrade), feniman@usp.br (M.R. Feniman), apfukushiro@gmail.com (A.P. Fukushiro),gfelix@ usp.br (G. Berretin-Felix), lumaximino@uol.com.br (L.P. Maximino).
}

Disturbances of respiratory function in children are still related to impairment of attention [4], visual perception, memory [5] and phonological processing [6,7]. In addition to psycholinguistic abilities, studies suggest a direct correlation with the Oral Language, at the level of expressive vocabulary [6-9], receptive vocabulary [10], phonological level [8], verbal fluency [11] and Global Expressive Language $[6,7,12]$.

It was observed that oral breathing and Obstructive Sleep Apnea may also be related to altered auditory processing in children, specifically in the abilities of temporal ordering and background figure for verbal sounds [13].

In cases which the respiratory mode affects the quality of sleep, owing to deprivation of an adequate sleep, compromising of health and body functioning is possible. For the measurement of sleep quality, the Obstructive sleep apnea-18-item questionnaire (OSA18) which assists in the clinical management of these cases, by measuring sleep quality of life, was elaborated [14-18]. 
Due to the findings in the literature associating the impairment of orofacial myofunctional aspects, auditory processing and verbal skills with sleep disorders, we sought to investigate speechlanguage disorders that may be associated with poor sleep quality in children.

Thus, the present research aimed at correlating children's sleep quality of life with oral language skills, auditory processing and orofacial myofunctional aspects.

\section{Methods}

The study was approved by the Research Ethics Committee of the institution involved (number CAAE 13033313.3.0000.5417), and only the children whose parents/guardians signed the informed consent, were submitted to the proposed procedures.

\subsection{Sample}

The study included 19 children, 12 males and 7 females, aged 7 to 12 , the mean age being 9.26 years ( $d p 1.85$ ). The children were evaluated by an otorhinolaryngologist, so as to identify possible conductive factors in the peripheral auditory pathway (a prerequisite for conventional audiology and auditory processing assessment). This professional also performed rhinoscopy and oroscopy, investigating structural characteristics that could interfere with the respiratory function.

Inclusion criteria: age between seven and 12 years; no alteration in the medical evaluation for the performance of the proposed tests; no neurological changes; auditory thresholds of frequencies $500 \mathrm{~Hz}, 1000 \mathrm{~Hz}, 2000 \mathrm{~Hz}$ and $4000 \mathrm{~Hz}$ within normality patterns and type A tympanometric curve.

Exclusion criteria: children who did not complete all the evaluations performed by the Otorhinolaryngologist and SpeechLanguage Therapist (in the fields of Orofacial Motricity, Language and Audiology).

The speech-language evaluation was performed in two visits with a total duration of $3 \mathrm{~h}$, in each child, not exceeding the maximum period of two weeks to complete the assessments.

\subsection{Procedures}

\subsubsection{Sleep quality of life}

The Brazilian Portuguese version of questionnaire OSA-18 [19] was applied to the caregivers/responsible for the children, aiming at quantifying the quality of sleep. In order to do this, five domains were evaluated: sleep disturbance (four items with scores varying from 4 to 28), physical symptoms (four items with scores ranging from 4 to 28), emotional symptoms (three items with scores ranging from 3 to 21), daytime function (three items with scores varying from 3 to 21) and - caregiver concerns (four items with scores ranging from 4 to 28 ). The total score of OSA-18, therefore, ranged from 18 to 126 [15], and the higher the scores, the worse the quality of life of sleep.

\subsubsection{Auditory processing assessment}

Audiologic evaluation (Pure-Tone Threshold Audiometry, Speech audiometry and Immittance) was performed prior to the auditory processing evaluation, and all the children presented tonal thresholds equal or inferior to $15 \mathrm{dBNHL}$ between frequencies $250 \mathrm{~Hz}$ and $8 \mathrm{kHz}$, Type A tympanometric curve, and Speech audiometry compatible with Pure-Tone Threshold Audiometry, bilaterally.

The following instruments were used, in order to evaluate the auditory abilities: Memory test for verbal and non-verbal sounds in sequence, to verify the ability of temporal ordering; Dichotic Digits
Test for background figure ability for verbal sounds; Nonverbal Dichotic Test to verify the background figure ability for nonverbal sounds [20], and the Sustained Auditory Attention Ability Test [21], to assess the ability of sustained auditory attention.

\subsubsection{Evaluation of phonological processing}

The Phonological Awareness Profile test [22] was applied aiming at evaluating the phonological awareness performance, through the phonological abilities that it covers (analysis, addition, segmentation, subtraction, substitution, rhyme, sequential rhyme, syllabic reversal and articulatory image).The Rapid Automatized Naming (RAN) consists of a set of tests that allow to establish parameters of the speed at which the lexicon is accessed in different semantic groups: colors, letters, digits and objects [23]. Thus, the children were asked to name the figures as quickly as they could. The evaluator used a timer to calculate the time in which the child named each semantic category.

The Phonological Work Memory aimed at assessing the processing and storage of information, nonwords and digits, in the short term [24]. The evaluator emitted sequences of nonwords and digits, to be repeated by the volunteer. Two chances were given for each sequence to be properly repeated.

It is emphasized that the three evaluations above are related to phonological processing, indicating the performance for the execution of complex cognitive activities such as comprehension, learning and written language [25].

\subsubsection{Language evaluation - phonological and lexical level}

Phonology and vocabulary were evaluated with the proofs of naming and imitation of words and lexical competence (categories: clothing, animals, food, transportation, furniture and utensils, professions, places, shapes and colors, toys and musical instruments) of the ABFW Children's Language Test [26].

\subsubsection{Orofacial myofunctional evaluation and anthropometric measurements}

The children were submitted to the following tests of the MBGR orofacial myofunctional MBGR exam [27]: aspects of the teeth, habitual posture analysis, aspect of tongue and mobility of lips, tongue, cheeks and soft palate; tonicity of lips, tongue and cheeks, assigning the scores of 0 for normality up to 3 points (worst condition), varying for each item. Regarding the orofacial functions, the breathing was evaluated, as to the type, mode and possibility of nasal use, and speech, also being attributed scores from the analysis of saliva aspects, mouth opening, tongue position, labial and mandibular movement, resonance, articulatory precision, velocity and pneumo-phono-articulatory coordination.

The anthropometric measurements of the children were also recorded: weight, height, and cervical circumference. The body mass index (BMI), which is determined by the ratio of mass (in kilograms) of the individuals by the square of their height (in meters), was calculated as well.

\subsection{Analysis of results}

The results of the evaluations were analyzed using the MannWhitney test for the quantitative variables (percentages and scores). Fisher's exact test was used for comparison between qualitative variables. Spearman correlation was used to compare all variables with the results of the OSA-18 sleep quality questionnaire.

Values from -1 to 1 , where the value suggests the strength of the relationship between the variables and the signal indicates the positive or negative direction of their relationship, were used in order to verify the correlation coefficient. Values ranging from 0.10 to 0.30 show a weak correlation between the variables [28]; 
between 0.40 and 0.60 , a moderate correlation, and; from 0.70 to 1 , a strong one. In all tests, the rejection level of the null hypothesis adopted was $5 \%(\mathrm{p}<0.05)$.

\section{Results}

The present study aimed at investigating children's sleep quality, so as to compare it with their communicative abilities. The OSA18 overall score data expressed an average consistent with a mild impact on the quality of life (Table 1 ).

No significant correlation was seen, by relating the results of OSA-18 to the auditory processing tests (memory test for verbal sounds in sequence, memory test for non-verbal sounds in sequence, dichotic digit tests, non-verbal dichotic tests, sustained auditory attention ability test).

Regarding Phonological Processing, considering the quantitative results, a significant relation was observed for backward digits (Table 3).

For the evaluation of phonology and vocabulary, the children were divided into two groups, the first not presenting alterations in these tests, comprising 11 children ( 5 males and 6 females), and the second group consisted of 8 children ( 7 males and 1 female) that presented alteration.

The children who presented alterations in phonology or vocabulary were compared to those with no change, in relation to OSA-18 scores and the following p values were obtained: Domain 1-0.84; Domain 2-0.11; Domain 3-0.66; Domain 4-0.91; Domain 5-0.04; Visual Analogue Scale - 0.00 and Global Score - 0.051 . Therefore, there was a difference between the groups for domain 5 and in the visual analogue scale, demonstrating that parents' concerns and perception about the sleep quality of children with language impairment were more impaired when compared to the group of children with no language alteration.

A statistical difference was observed for three items (Table 4), in the assessment of orofacial motricity.

For the aspects in which a statistically significant difference was observed (Phonological work memory regarding phonological processing and mandible and lip mobility of the Orofacial Myofunctional Assessment), the statistical analysis was performed by correlating these aspects with each domain, visual analogue scale and OSA-18 global score (Table 5).

\section{Discussion}

Considering the importance of understanding the general wellbeing of the child, such as the aspect of sleep quality, and its relation with the performance of speech-language skills, the present study sought to establish possible correlations, making it possible to improve the diagnosis and treatment of communication disorders.

It was verified that the answers of the parents/guardians of the children belonging to the sample of this study (Table 1) determined a lower global score value than the study of the translation of this
Table 2

Correlation between OSA-18 score data and the auditory processing assessment.

\begin{tabular}{llll}
\hline & Mean & $\mathrm{R}$ & $\mathrm{p}$ \\
\hline MTVS & 2,11 & $-0,34$ & 0,15 \\
MTNVS & 2,53 & $-0,16$ & 0,52 \\
DDT (RE) & 94,90 & $-0,15$ & 0,55 \\
DDT (LE) & 94,13 & $-0,15$ & 0,56 \\
NVDT - Free listening (RE) & 11,56 & 0,17 & 0,51 \\
NVDT - Free listening (LE) & 12,00 & $-0,28$ & 0,26 \\
NVDT - Directed attention (RE) & 21,67 & $-0,12$ & 0,64 \\
NVDT - Directed attention (LE) & 1,56 & 0,03 & 0,92 \\
SAAAT - Total score & 19,06 & 0,28 & 0,27 \\
SAAAT - Decrease of vigilance & 2,17 & 0,21 & 0,40 \\
\hline
\end{tabular}

RE - Right ear; LE - Left ear; MTVS - Memory test for verbal sounds in sequence; MTNVS - Memory test for nonverbal sounds in sequence; DDT - Dichotic Digits Test; NVDT - Nonverbal Dichotic Test; SAAAT - Sustained Auditory Attention Ability Test. Statistical test: Spearman correlation; $\mathrm{p}<0,05$.

questionnaire into the Portuguese language of the OSA-18 questionnaire [19]. The reason is that, in this study, the questionnaire was applied to a population that not necessarily presented respiratory complaints.

In the literature, a relationship was found between children who presented obstructive sleep Apnea/Hypopnea Syndrome in the memory test for non-verbal sounds in sequence and dichotic digit test [13], which was not observed in this study (Table 2), since the quality of sleep verified using the OSA-18 questionnaire did not correlate with any of the auditory processing tests applied to this sample. It should be emphasized that sleep evaluation in a previous study [13] was performed through polysomnography, which was a limitation of the procedures used in the present study. In addition, it should be emphasized that auditory alterations may be related to the history of chronic middle otitis frequently observed newborns with physiologic gastroesophageal reflux, which is related to obstructive sleep disorders [29].

In relation to phonological processing, a moderate correlation of OSA-18 (Table 1) with phonological work memory was observed for backward digits (Tables 3 and 5), indicating that the higher the scores in backward digits, the lower the score of OSA-18. Studies also showed a correlation between phonological processing and sleep disorders, but they used polysomnography as the instrument for sleep parameters assessment $[5,9]$.

Poor sleep quality can affect memory, especially working memory [30]. In a study with patients diagnosed with obstructive sleep apnea, it was found that executive function skills are more impaired than basic cognitive abilities [31]. The executive function is not totally affected in patients with OSA, since some abilities may be altered while others may not [32]. Studies comparing groups of patients with OSA and controls group in working memory tests using the digit repetition test results found lower in the group with OSA compared with the control group, both in the repetition in direct order and in reverse order [33-37].

In a test that evaluates working memory using digit repetition, it was easier for subjects to remember digits in the direct order than

Table 1

Results of OSA-18 overall score data, considering a mean, medium, standard deviation, minimum and maximum value.

\begin{tabular}{|c|c|c|c|c|c|}
\hline & Mean & Medium & Minimum & Maximum & Standard deviation \\
\hline Domain 1 - Sleep disturbance & 4,95 & 4,00 & 4 & 10 & 1,55 \\
\hline Domain 2 - Physical symptoms & 5,74 & 4,00 & 4 & 14 & 2,62 \\
\hline Domain 3 - Emotional symptoms & 4,47 & 3,00 & 3 & 12 & 2,63 \\
\hline Domain 4 - Daytime function & 6,42 & 5,00 & 3 & 15 & 3,64 \\
\hline Domain 5 - Caregiver concerns & 5,21 & 4,00 & 4 & 13 & 2,32 \\
\hline Visual analogue scale & 8,03 & 8,00 & 0 & 10 & 2,32 \\
\hline Total score & 26,79 & 23,00 & 18 & 47 & 8,89 \\
\hline
\end{tabular}


Table 3

Correlation between OSA-18 with phonological processing tests.

\begin{tabular}{|c|c|c|c|c|c|c|c|c|}
\hline & \multirow[t]{2}{*}{ Profile test } & \multicolumn{3}{|c|}{ Phonological work memory } & \multicolumn{4}{|l|}{ RAN } \\
\hline & & Nonwords & Digits in direct order & Digits in reverse order & Objects & Letters & Digits & Colors \\
\hline Mean/Normality & 64,17 & 64,16 & 15,47 & 9,00 & 7 & 9 & 6 & 13 \\
\hline $\mathbf{R}$ & $-0,30$ & $-0,44$ & $-0,37$ & $-0,46$ & - & - & - & - \\
\hline $\mathbf{p}$ & 0,23 & 0,06 & 0,12 & 0,04 & 0,15 & 0,17 & 0,18 & 0,32 \\
\hline
\end{tabular}

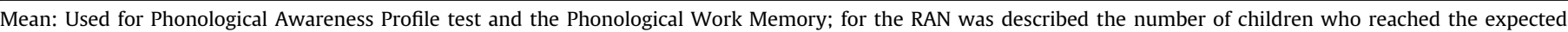
parameters for their age group. Statistical test for Perfil e Memória de Trabalho Fonológica: Spearman correlation; $\mathrm{p}<0,05 ;$ Statistical test for RAN: Fisher Test, $\mathrm{p}<0,05$.

Table 4

Correlation between OSA-18 and MBGR protocol.

\begin{tabular}{lllll}
\hline & Mean & $\mathrm{R}$ & $\mathrm{p}$ \\
\hline \multirow{6}{*}{ BMI } & 18,17 & 0,16 & 0,52 \\
& CC & 29,13 & 0,50 & 0,84 \\
& IDMO & 43,39 & 0,09 & 0,70 \\
& IDMOTS & 27,82 & $-0,11$ & 0,65 \\
VOnicity & 2,24 & 0,08 & 0,75 \\
& HO & 3,27 & 0,08 & 0,73 \\
& Teeth & 2,79 & 0,01 & 0,97 \\
& Lingual frenulum & 1,42 & 0,11 & 0,64 \\
& Tonus & 2,84 & 0,26 & 0,28 \\
& Breathing & 2,00 & 0,50 & $\mathbf{0 , 0 3}$ \\
& Mandible & 0,42 & 0,51 & $\mathbf{0 , 0 3}$ \\
& Lips & 2,63 & 0,45 & $\mathbf{0 , 0 5}$ \\
& Lips & 9,58 & 0,47 & $\mathbf{0 , 0 4}$ \\
& Cheeks & 4,89 & 0,14 & 0,58 \\
& Soft palate & 1,26 & 0,02 & 0,92 \\
& Tongue & 15,68 & 0,30 & 0,21 \\
& Speech & 2,42 & 0,25 & 0,29 \\
\hline
\end{tabular}

BMI - Body mass index; CC - Cervical circumference; IDMO - Interincisal distance of mouth opening; IDMOTS - Interincisal distance of mouth opening with the tongue support; VO - vertical overlap; HO - horizontal overlap. Statistical test: Spearman correlation; $\mathrm{p}<0,05$.

Table 5

Correlation between Phonological Work Memory, mandible and lip mobility with OSA-18 domains.

\begin{tabular}{|c|c|c|c|c|c|c|}
\hline & \multicolumn{2}{|c|}{$\begin{array}{l}\text { PWM digits } \\
\text { in direct } \\
\text { order }\end{array}$} & \multicolumn{2}{|c|}{ Mandible } & \multicolumn{2}{|l|}{ Lips } \\
\hline & $\mathrm{R}$ & $\mathrm{p}$ & $\mathrm{R}$ & $\mathrm{p}$ & $\mathrm{R}$ & $\mathrm{p}$ \\
\hline (D - 1) Sleep disturbance & $-0,41$ & 0,08 & 0,25 & 0,30 & 0,43 & 0,07 \\
\hline (D - 2) Physical symptoms & $-0,28$ & 0,24 & 0,51 & $\mathbf{0 , 0 2}$ & 0,21 & 0,38 \\
\hline (D - 3) Emotional symptoms & $-0,40$ & 0,08 & 0,38 & 0,10 & 0,28 & 0,24 \\
\hline (D - 4) Daytime function & $-0,33$ & 0,17 & 0,32 & 0,18 & 0,33 & 0,17 \\
\hline (D - 5) Caregiver concerns & $-0,29$ & 0,22 & 0,43 & 0,06 & 0,40 & 0,09 \\
\hline Visual analogue scale & 0,59 & 0,01 & $-0,37$ & 0,12 & $-0,39$ & 0,10 \\
\hline Total score & $-0,46$ & 0,04 & 0,51 & $\mathbf{0 , 0 2}$ & 0,47 & 0,04 \\
\hline
\end{tabular}

PWM - Phonological Work Memory; D - Domínio. Statistical test: Spearman correlation; $\mathrm{p}<0,05$.

in the reverse order. This is due to the complexity of the task because in the reverse order there is recruitment of the central executive system (regulates the information flow, processes and stores) and in the direct order with the phonological loop (stores and manipulates speech-based material) $[38,39]$.

The present study shows that expressive oral language skills related to OSA-18. In the literature, these skills are related to sleep disorders at the expressive vocabulary [6-9] and phonological levels [8], however, one shortcoming of these studies is that the basic audiology assessment to verify the hearing of the children evaluated was not carried out.

The orofacial aspects and functions showed a moderate correlation with the OSA-18 (Tables 4 and 5), with the breathing function, and the aspects of mandible posture and lip mobility, corroborating previous findings $[1,40,41]$ that differ in their methods for presenting the gold standard examination (polysomnography). This fact may possibly be justified by the respiratory pattern of the children in this sample, which may be an oronasal pattern during sleep, thus, interfering with parents' complaints regarding domain 2 (physical symptoms) and overall score of OSA18.

Speech and language assessments should not only consist in raising complaints of the patients or those responsible for them, but also verify correlated factors that may interfere with or be causal factors in the complaints of these patients. Aspects related to sleep represent important data in the speech-language therapy anamnesis, since these data may be related to a range of speechlanguage therapy aspects already reported in the literature $[1,6-9,13,40,41]$.

It is worth emphasizing the limitation of this study by the reduced casuistry, besides the impossibility of performing the polysomnography, which would provide diversified physiological parameters of the child's sleep. Further investigation is suggested in this regard, using the reverse as the guide, studying children diagnosed with respiratory changes.

\section{Conclusion}

A relationship was seen between sleep quality and speechlanguage skills in children aged 7-12 years, using the OSA-18 questionnaire, with a correlation of this instrument with the phonological processing skills, specifically in the memory of Phonological work of backward digits, and with orofacial myofunctional aspects, as for breathing, jaw and lip mobility.

\section{References}

[1] A. Branco, G.F. Ferrari, S.A.T. Weber, Orofacial alterations in allergic diseases of the airways, Rev. Paul. Pediatr. 25 (2007) 266-270.

[2] S.C. Izu, C.H. Itamoto, M. Pradella-Hallinan, G.U. Pizarro, S. Tufik, S. Pignatari, et al., Obstructive sleep apnea syndrome (OSAS) in mouth breathing children, Braz J. Otorhinolaryngol. 76 (2010) 552-556.

[3] R.C. Di Francesco, G. Passerotii, B. Paulucci, A. Miniti, Mouth breathing in children: different repercussions according to the diagnosis, Braz J. Otorhinolaryngol. 70 (2004) 665-670.

[4] S.A.T. Weber, A.C. Lima Neto, F.J.S. Ternes, J.C. Montovani, Hyperactivity and attention deficit syndrome in obstructive sleep apnea syndrome: is there improvement with surgical management? Braz J. Otorhinolaryngol. 72 (2006) 124-129.

[5] S.F. Hamasaki Uema, S.S. Nagata Pignatari, R.R. Fujita, G.A. Moreira, M. Pradella-Hallinan, L. Weckx, Assessment of cognitive learning function in children with obstructive sleep breathing disorders, Braz J. Otorhinolaryngol. 73 (2007) 315-320.

[6] K. Liukkonen, P. Virkkula, A. Haavisto, A. Suomalainen, E.T. Aronen, A. Pitkäranta, et al., Symptoms at presentation in children with sleep-related disorders, Int. J. Pediatr. Otorhinolaryngol. 76 (2012) 327-333.

[7] L.M. O'Brien, C.B. Mervis, C.R. Holbrook, J.L. Bruner, C.J. Klaus, J. Rutherford, et al., Neurobehavioral implications of habitual snoring in children, Pediatrics 114 (2004) 44-49.

[8] G. Andreou, P. Agapitou, Reduced language abilities in adolescents who snore Arch. Clin. Neuropsychol. 22 (2007) 225-229.

[9] S.M. Honaker, D. Gozal, J. Bennett, O.S. Capdevila, K. Spruyt, Sleep-disordered breathing and verbal skills in school-aged community children, Dev. Neuropsychol. 34 (2009) 588-600. 
[10] O. Yorbik, C. Mutlu, D. Koc, T. Mutluer, Possible negative effects of snoring and increased sleep fragmentation on developmental status of preschool children, Sleep. Biol. Rhythm 12 (2014) 30-36.

[11] Y.E. Landau, O. Bar-Yishay, S. Greenberg-Dotan, A.D. Goldbart, A. Tarasiuk, A. Tal, Impaired behavioral and neurocognitive function in preschool children with obstructive sleep apnea, Pediatr. Pulmonol. 47 (2012) 180-188.

[12] P. Kurnatowski, L. Putyński, M. Lapienis, B. Kowalska, Neurocognitive abilities in children with adenotonsillar hypertrophy, Int. J. Pediatr. Otorhinolaryngol. 70 (2006) 419-424.

[13] K.N. Ziliotto, M.F.C. dos Santos, V.G. Monteiro, M. Pradella-Hallinan, G.A. Moreira, L.D. Pereira, et al., Auditory processing assessment in children with obstructive sleep apnea syndrome, Braz J. Otorhinolaryngol. 72 (2006) $321-327$.

[14] L.M. de Serres, C. Derkay, S. Astley, R.A. Deyo, R.M. Rosenfeld, G.A. Gates, Measuring quality of life in children with obstructive sleep disorders, Arch. Otolaryngol. Head. Neck Surg. 126 (2000) 1423-1429.

[15] A.M. Strocker, A. Carrer, N.L. Shapiro, The validity of the OSA-18 among three groups of pediatric patients, Int. J. Pediatr. Otorhinolaryngol. 69 (2005) $241-247$.

[16] V.C. Silva, A.J.M. Leite, Quality of life in children with sleep-disordered breathing: evaluation by OSA-18, Braz J. Otorhinolaryngol. 72 (2006) 747-756.

[17] G.M.S. Nascimento, D.C. Salgado, M.S. Maia, E.E. Lambert, M.R.B. Pio, R. Suzano, et al., Impacto do tratamento cirúrgico na qualidade de vida de crianças com hiperplasia de tonsilas, Acta ORL 25 (2007) 119-123.

[18] J.M. Lima Jr., V.C. Silva, M.R. Freitas, Long term results in the life quality of children with obstructive sleep disorders, Braz J. Otorhinolaryngol. 74 (2008) $718-724$.

[19] F.M.V.S. Fernandes, R.C.V.V. Teles, Application of the Portuguese version of the obstructive sleep Apnea-18 survey to children, Braz J. Otorhinolaryngol. 79 (2013) 720-726

[20] L.D. Pereira, E. Schochat, Testes Auditivos Comportamentais Para avaliação do Processamento Auditivo Central, 2011. Barueri Pró-Fono.

[21] M.R. Feniman, R.R. Ortelan, J.R.P. Lauris, C.F. Campos, M.S. Cruz, A proposed behavioral tool to assess sustained auditory attention, Braz J. Otorhinolaryngol. 73 (2007) 523-527.

[22] A.M.M.A. Alvarez, I.A.M. Carvalho, A.L. Caetano, Perfil de Habilidades Fonológicas, 2. ed., Via Lettera, São Paulo, 2004.

[23] T.L. Ferreira, J.M.F. Tonelotto, S.M. Ciasca, S.A. Capellini, Desempenho de escolares leitores proficientes no teste de nomeação automatizada rápida (RAN), Temas sobre Desenvolv. 12 (2003) 26-32.

[24] S.R.V. Hage, M.A. Grivol, Desempenho de crianças normais falantes do português em prova de memória de trabalho fonológica, Cad. Comunicação
Ling. 1 (2009) 61-72.

[25] J.W. Montgomery, Working memory and comprehension in children with specific language impairment: what we know so far, J. Commun. Disord. 36 (2003) $221-231$.

[26] C.R.F. Andrade, D.M. Befi-Lopes, F.D.M. Fernandes, H.F. Wertzner, ABFW: Teste de Linguagem Infantil nas áreas de Fonologia, vocabulário, fluência e pragmática, 2. ed., Pró-Fono, Barueri, 2004.

[27] K.F. Genaro, G. Berretin-Felix, M.I.B.C. Rehder, I.Q. Marchesan, Orofacial myofunctional evaluation - MBGR protocol, Rev. CEFAC 11 (2009) 237-255.

[28] C. Dancey, J. Reidy, Estatística sem Matemática para Psicologia: Usando SPSS para Windows, Artmed, Porto Alegre, 2006.

[29] A. Serra, S. Cocuzza, G. Poli, I. La Mantia, A. Messina, P. Pavone, Int. J. Pediatr. Otorhinolaryngol. 71 (2007) 1693-1697.

[30] P. Valdez, T. Reilly, J. Waterhouse, Rhythms of mental performance, Mind Brain Educ. 2 (2008) (2008) 7-16.

[31] D.W. Beebe, D. Gozal, Obstructive sleep apnea and the pré-frontal cortex: towards a comprehensive model linking nocturnal upper airway obstruction to daytime cognitive and behavioural deficits, J. Sleep. Res. 11 (2002) 1-16.

[32] P.W. Burgess, Assessment of executive function, in: P.W. Halligan, U. Kischka, J.C. Marshall (Eds.), Handbook of Clinical Neuropsychology, University Press, 2003, pp. 302-321.

[33] B. Naegele, V. Thouvard, J.L. Pepin, et al., Deficits of cognitive executive functions in patients with sleep apnea syndrome, Sleep 18 (1995) 43-52.

[34] C. Feuerstein, B. Naegele, J.L. Pepin, P. Levy, Frontal loberelated cognitive function in patients with sleep apnea syndrome before and after treatment, Acta Neurol. Belg 97 (1997) 96-107.

[35] S. Redline, M.E. Strauss, N. Adams, et al., Neuropsychological function in mild sleep-disordered breathing, Sleep 20 (1997) 160-167.

[36] E. Verstraeten, R. Cluydts, D. Pevernagie, G. Homann, Executive function in sleep apnea: controlling for attentional capacity in assessing executive attention, Sleep 27 (2004) 685-693.

[37] I. Rouleau, A. Decary, A.J. Chicoine, J. Montplaisir, Procedural skill learning in obstructive sleep apnea syndrome, Sleep 25 (2002) 401-411.

[38] V.L. Figueiredo, E. Nascimento, Desempenhos nas duas tarefas do subteste dígitos do WISC-III e do WAIS-III, Psicol. Teor. Pesqui. 23 (2007) 313-318.

[39] A. Baddeley, The episodic buffer: a new component of working memory? Trends Cogn. Sci. 4 (2000) 417-423.

[40] F.C. Pereira, S.M. Motonaga, P.M. Faria, M.A.N. Matsumoto, L.Y.V. Trawitzki, S.A. Lima, et al., Myofunctional and cephalometric evaluation of mouth breathers, Braz J. Otorhinolaryngol. 67 (2001) 43-49.

[41] T.V.C. Perilo, A.R. Motta, E.B. Las Casas, J.M.E. Saffar, C.G.C. Costa, Objective evaluation of axial forces produced by the tongue of oral breathing children, Rev. Soc. Bras. Fonoaudiol. 12 (2007) 184-190. 